\title{
Unilateral Chronic Thromboembolic Pulmonary Hypertension - A Case Report of Unusual Presentation of CTEPH
}

\author{
Nihar Mehta ${ }^{1}$, Nikesh Jain ${ }^{2 *}$, Sanjeev Vichare ${ }^{3}$ and Ajit Desai ${ }^{4}$ \\ ${ }^{1}$ Consultant Cardiologist, Jaslok Hospital and Research Centre, India \\ ${ }^{2} J u n i o r$ Consultant Cardiologist, Jaslok Hospital and Research Centre, India \\ ${ }^{3}$ Consultant CVTS Surgeon, Jaslok Hospital and Research Centre, India \\ ${ }^{4}$ Department of Cardiology, Jaslok Hospital and Research Centre, India
}

Submission: July 29, 2019; Published: August 19, 2019

*Corresponding author: Nikesh Jain, Junior Consultant Cardiologist, Jaslok Hospital and Research Centre, Mumbai 4000070, Maharashtra, India

\begin{abstract}
Chronic thromboembolic pulmonary hypertension categorized as group IV pulmonary according to World Health Organization, is defined as mean pulmonary arterial pressure of more than $25 \mathrm{~mm} \mathrm{Hg}$ that persists inspite of more than 6 months of anticoagulation in presence of persistent pulmonary thrombi. Chronic thromboembolic pulmonary hypertension is an uncommon and potentially fatal sequelae of acute pulmonary embolism. It is usually diagnosed in late stage due to lack of early diagnosis and carry poor prognosis if definitive treatment is not given. As compared to other categories of pulmonary hypertension, chronic thromboembolic hypertension is potentially curable with pulmonary endarterectomy. The usual presentation is bilateral pulmonary artery involvement. We describe an unusual presentation of unilateral pulmonary artery involvement in a patient with Factor V Leiden mutation. Patient was successfully treated with pulmonary endarterectomy.
\end{abstract}

Keywords: Unilateral chronic thromboembolic pulmonary hypertension; Pulmonary endarterectomy; Unilateral pulmonary involvement; Thrombophilia

\section{Introduction}

CTEPH occurs in $3.8-4.8 \%$ of patients following acute pulmonary embolism [1,2]. It is defined as mean pulmonary arterial pressure of more than $25 \mathrm{mmHg}$ persisting for more than 6 months inspite of adequate anticoagulation. It is categorized as group IV as per WHO category of pulmonary hypertension [3].

CTEPH is a pre-capillary pulmonary hypertension resulting from persistent thrombus in pulmonary artery which becomes fibrotic and flow limiting. Though it is a sequela of acute pulmonary embolism many patients do not give such history and present in chronic stage.

CTEPH is usually diagnosed in its late stage and carry a poor prognosis if untreated. Pulmonary endarterectomy can effectively cure CTEPH and is the only curable cause of severe pulmonary hypertension. Patients who are not candidates of pulmonary endarterectomy, in select patients balloon pulmonary angioplasty can be offered to patients [4-6].
Usually in CTEPH bilateral pulmonary arteries are involved. Unilateral CTEPH is a very uncommon presentation. We describe an unusual case of unilateral CTEPH which was successfully treated with pulmonary endarterectomy.

\section{Case Report}

We present the case of 48-year-old gentleman, chronic smoker, no other comorbidities, who presented to us with exertional breathlessness, now in NYHA class III and hemoptysis.

On evaluation for exertional breathlessness 5 months back, patient was found to have DVT of lower limb with pulmonary thromboembolism. Patient's CT scan of chest showed complete thrombotic occlusion of left pulmonary artery and partial filling defect in right posterior basal segmental branch of pulmonary artery. Patient was thrombolysed and started on oral anticoagulation. Due to persistent symptoms and thrombus demonstrated on follow-up CT scan, a retrievable IVC filter was inserted and oral anticoagulation continued. 


\section{Journal of Cardiology \& Cardiovascular Therapy}

Patient now presented with worsening symptoms and hemoptysis. His CT Chest showed persistent complete occlusion of left pulmonary at its origin with thrombus extension upto subsegmental branches and partial filling defect in right posterobasal segmental branch of right pulmonary artery (Figure $1 \& 2$ ). 2D Echocardiography showed normal LV function, Dilated RA/RV, RV dysfunction (TAPSE - 9mm, RVSM - 7cm/s), PASP $60 \mathrm{mmHg}$ and moderate TR. Further investigations revealed factor $\mathrm{V}$ Leiden mutation positive. Cardiac catheterisation showed PAP - 49/24 (32) mmHg, high PVR (793.6dynes/ $\mathrm{cm}^{2}$ i.e. $9.92 \mathrm{WU}$ ) and normal cardiac index. Ventilation Perfusion Scan revealed perfusion defects in the entire left lung and lower lobe of the right lung (Figure 3). The patient underwent a bilateral pulmonary endarterectomy (Figure 4). His post-operative course was uneventful. Patient required assisted ventilation for 2 days and was discharged after 8 days on oral anticoagulation. Six month later the patient remains asymptomatic and 2D echocardiography showed normal RV function and no evidence of pulmonary hypertension on echocardiography.

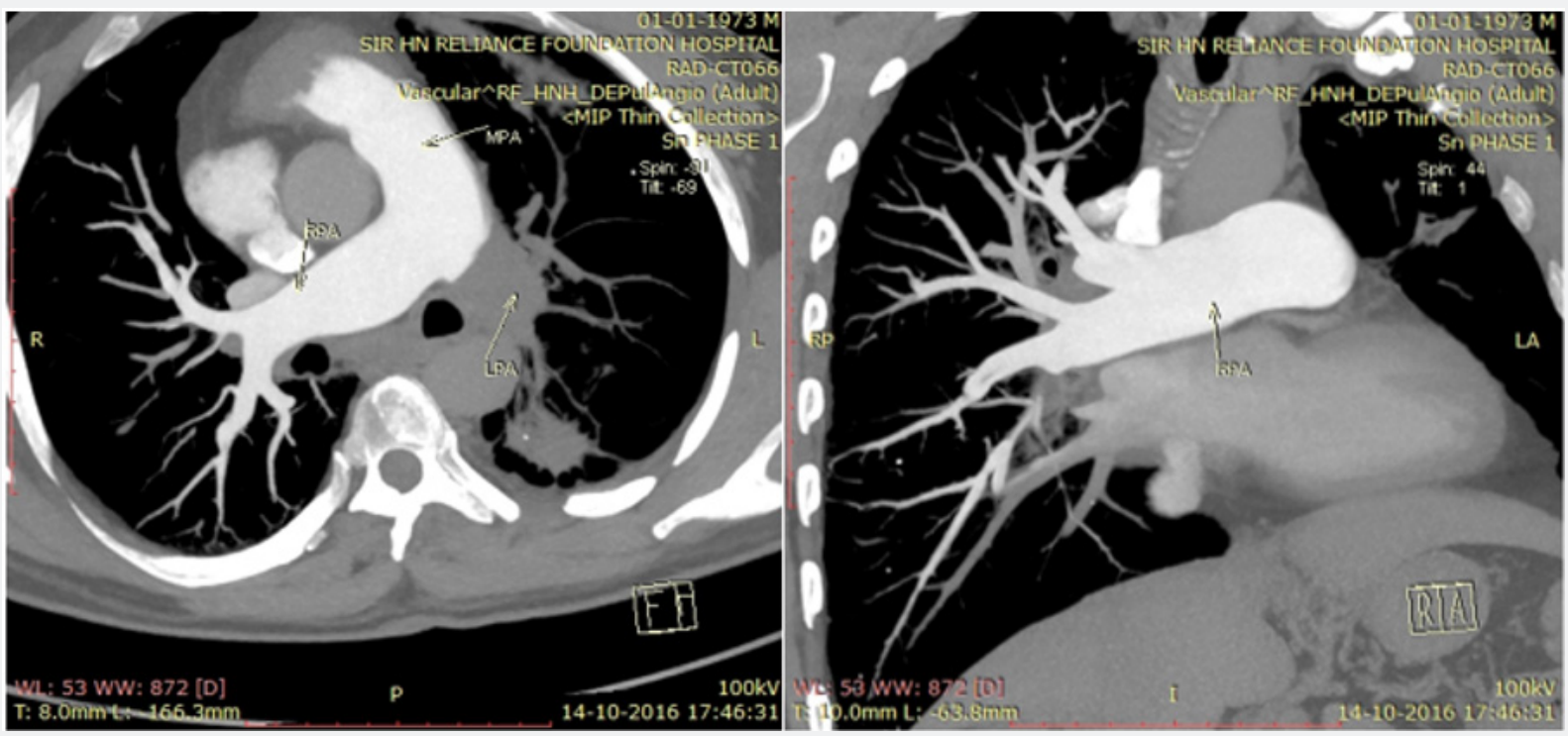

Figure 1: CT scan of the chest shows mildly dilated MPA, complete thrombotic occlusion of left pulmonary artery and partial occlusion of proximal posterior basal segmental branch of right lower lobar artery with subsegmental atelectasis in the anterior segment of left upper and subsegmental consolidation in left lower lobe.
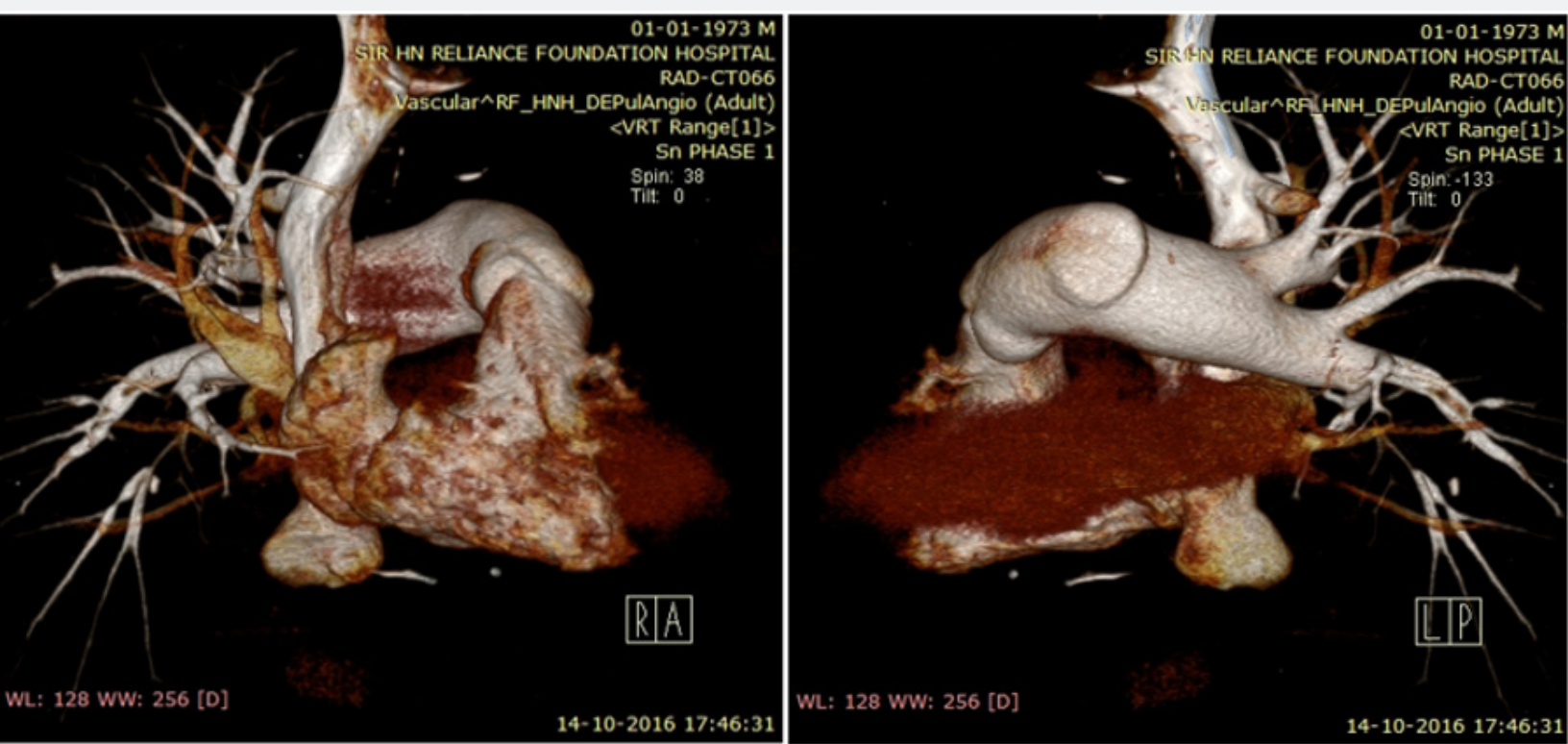

Figure 2: 3D reconstruction CT images showing complete thrombotic occlusion of left pulmonary artery and partial occlusion of proximal posterior basal segmental branch of right lower lobar artery. 


\section{Journal of Cardiology \& Cardiovascular Therapy}

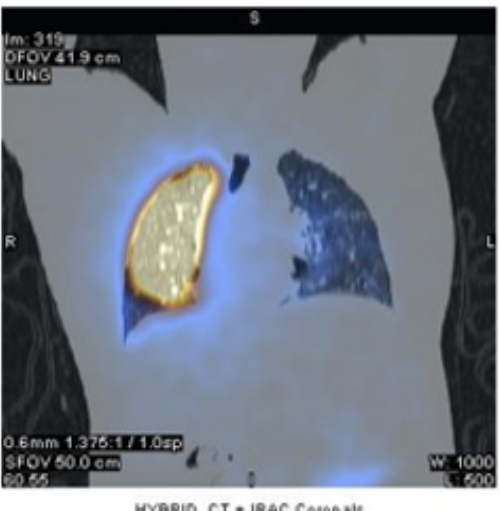

HYRIO_CT + IRAC COHORali

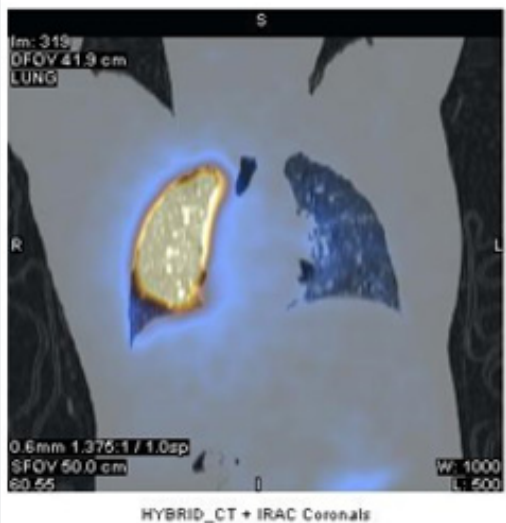

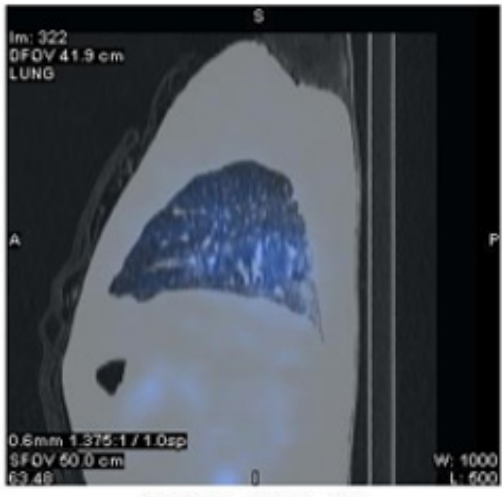

MVERID_CT + IRAC Sagitali

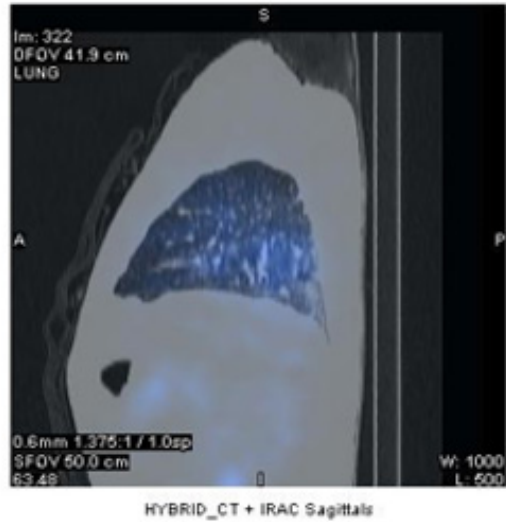

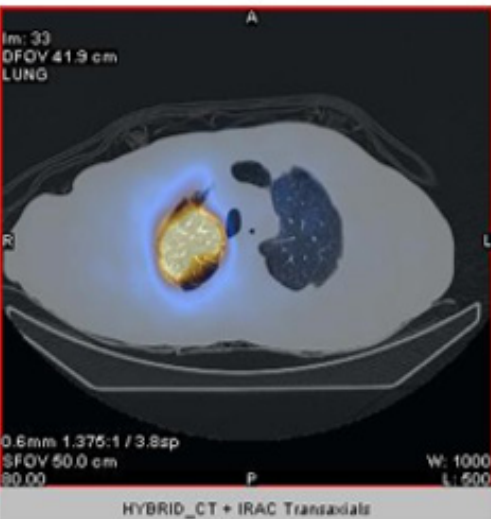

HVRID_CT + IRAC Tramadiais

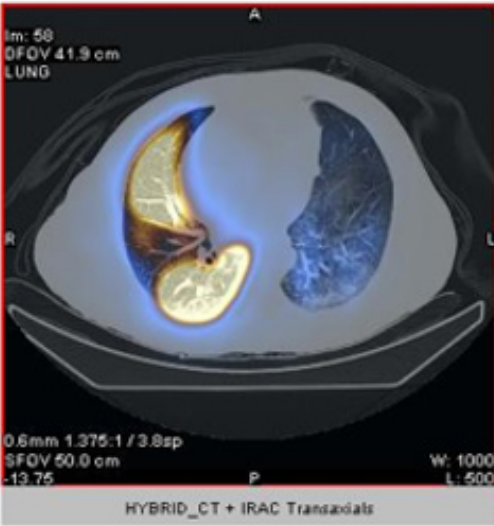

Figure 3: Lung perfusion/ventilation imaging (SPECT-CT) shows mismatched ventilation-perfusion defects seen in the entire left lung and in the posterobasal, lateral basal and anterior basal segment of lower lobe of right lung with normal ventilation.

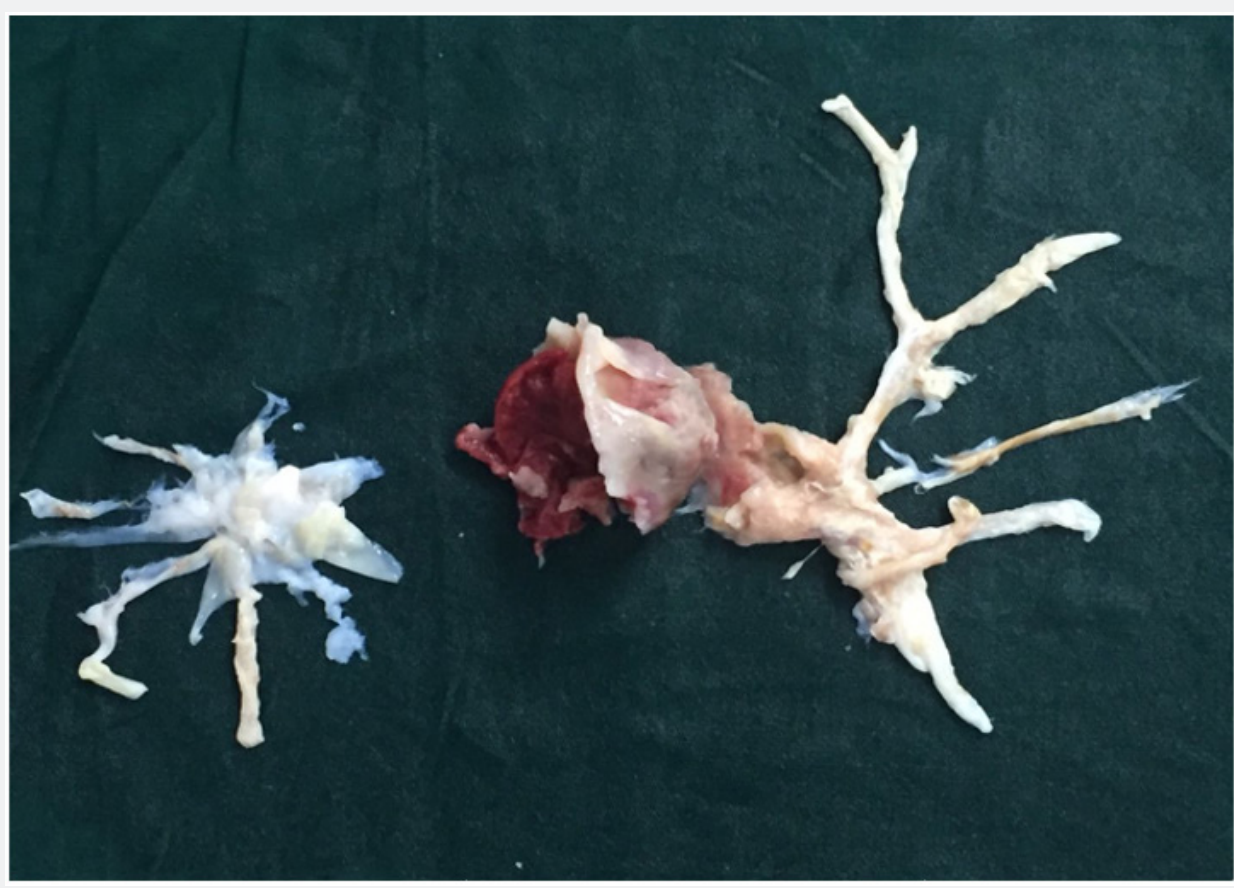

Figure 4: Pulmonary Endarterectomy done which showed completely occluded left pulmonary artery and segmental branch of right lobar artery. 


\section{Discussion}

CTEPH is an uncommon sequela of acute pulmonary embolism and is a potentially fatal condition. Pulmonary thromboendarterectomy is the gold standard treatment and surgically amenable patients should be referred to an experienced centre for treatment, with peri-procedural mortality of $2 \%$ to $5 \%$ at experienced centres [7]. Our case had an unusual unilateral presentation with Factor $V$ Leidin mutation which was successfully managed with pulmonary endarterectomy. There are only few case reports who had unilateral CTEPH and both the cases described had underlying thrombhophilia $[8,9]$. The exact pathophysiological mechanism behind unilateral presentation specifically with thrombhophilic states is not clear.

\section{References}

1. Pengo V, Lensing AW, Prins MH, Marchiori A, Davidson BL, et al. (2004) Incidence of chronic thromboembolic pulmonary hypertension after pulmonary embolism. N Engl J Med 350(22): 2257-2264.

2. Guerin L, Couturaud F, Parent F, Revel MP, Gillaizeau F, et al. (2014) Prevalence of chronic thromboembolic pulmonary hypertension after acute pulmonary embolism. Prevalence of CTEP after pulmonary embolism. Thromb Haemost 112(3): 598-605.

3. Simonneau G, Gatzoulis MA, Adatia I, Celermajer D, Denton C, et al. (2013) Updated clinical classification of pulmonary hypertension. J Am Coll Cardiol 62(25 Suppl): D34-D41.
4. Kataoka M, Inami T, Hayashida K, Shimura N, Ishiguro H, et al. (2012) Percutaneous transluminal pulmonary angioplasty for the treatment of chronic thromboembolic pulmonary hypertension. Circ Cardiovasc Interv 5(6): 756-762.

5. Mizoguchi H, Ogawa A, Munemasa M, Mikouchi H, Ito H, et al. (2012) Refined balloon pulmonary angioplasty for inoperable patients with chronic thromboembolic pulmonary hypertension. Circ Cardiovasc Interv 5(6): 748-755.

6. Satoh T, Kataoka M, Inami T, Ishiguro H, Yanagisawa R, et al. (2016) Endovascular treatment for chronic pulmonary hypertension: a focus on angioplasty for chronic thromboembolic pulmonary hypertension. Expert Rev Cardiovasc Ther 14(9): 1089-1094.

7. Madani MM, Auger WR, Pretorius V, Sakakibara N, Kerr KM, et al. (2012) Pulmonary endarterectomy: recent changes in a single institution's experience of more than 2,700 patients. Ann Thorac Surg 94(1): 97-103.

8. Lackzika K, Lang IM, Quehenberger P, Mannhalter C, Muhm M, et al. (2002) Unilateral chronic thromboembolic pulmonary disease associated with combined inherited thrombophilia. Chest 121(1): 286-289.

9. Suh JH, Park JH, Jeon YS, Kim JH, Ham BM, et al. (2003) Thromboendarterectomy in a Patient with Unilateral Chronic Thromboembolic Pulmonary Hypertension. Korean Journal of Anesthesiology 45(6): 797-801.

\begin{tabular}{|l|}
\hline Your next submission with Juniper Publishers \\
will reach you the below assets \\
- Quality Editorial service \\
- Swift Peer Review \\
- Reprints availability \\
- E-prints Service \\
- Manuscript Podcast for convenient understanding \\
- Global attainment for your research \\
- Manuscript accessibility in different formats \\
( Pdf, E-pub, Full Text, Audio) \\
- Unceasing customer service \\
Track the below URL for one-step submission \\
https://juniperpublishers.com/online-submission.php \\
\hline
\end{tabular}

